Iranian Quarterly Journal of Breast Disease. 2019, 12(1):39- 47 .

\section{Original Article \\ Diagnosis of Breast Cancer Subtypes using the Selection of Effective Genes from Microarray Data}

\author{
Tabatabaei $A^{1}$, Derhami $\mathbf{V}^{1 *}$, Sheikhpour $\mathbf{R}^{2}$, Pajoohan $M-R^{1}$ \\ ${ }^{1}$ Computer Engineering Department, Faculty of Engineering, Yazd University, Yazd, \\ Iran \\ 2 Department of Computer Engineering, Faculty of Engineering, Ardakan \\ University, Ardakan, Iran
}

Receive: 2019/2/13

Accepted: 2019/4/14

"Corresponding Author:

Vali Derhami

vderhami@yazd.ac.ir

Ethics Approval:

\begin{abstract}
Introduction: Early diagnosis of breast cancer and the identification of effective genes are important issues in the treatment and survival of the patients. Gene expression data obtained using DNA microarray in combination with machine learning algorithms can provide new and intelligent methods for diagnosis of breast cancer.

Methods: Data on the expression of 9216 genes from 84 patients across 5 different types of cancer was obtained using microarray technology. In this study, we proposed a feature selection method based on the correlation between abnormal expression of genes and cancer for diagnosis of breast cancer. Then, we used K-nearest neighbor (KNN), support vector machine (SVM), and naive Bayesian (NB) classifiers to evaluate the performance of the proposed method in the selection of relevant genes.
\end{abstract}

Results: The proposed feature selection method coupled with the KNN classifier predicted all types of cancer with $100 \%$ accuracy and using 38 of the 9216 genes. The proposed method could also identify the genes associated with each class. Moreover, the proposed feature selection method coupled with NB and SVM classifiers achieved accuracy rates of $90 \%$ and $96.67 \%$ using 17 and 22 genes, respectively.

Conclusion: The results of this study demonstrated that the proposed feature selection method has better performance compared with other methods. The proposed method is able to distinguish the genes involved in each cancer class and detect overexpression or underexpression of selected genes, which can be used by physicians and researchers in the field of health care.

Keywords: Breast Cancer, Feature Selection, Microarray Data, Classification 
مقاله برُوهشى تشخيص نوع سرطان بستان با استفاده از انتخاب زنهاى موثر از دادههاى

ريزآرايه

سيدابوالفضل طباطبايى'، ولى درهمى'،؛، راضيه شيخ يور '، محمدرضا يزوهان'

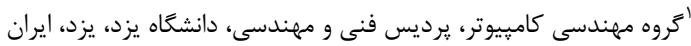

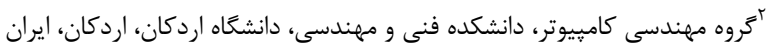

فصلنامه بيمارى هاى يستان ايران

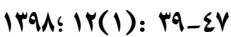

\section{olu?}

مقدمه: تشخيص زودهنگام سرطان يستان و زنهاى موثر در آن نقش بسيار كليدى در درمان و

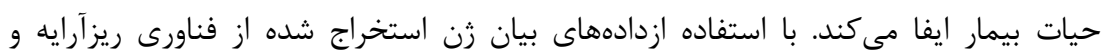

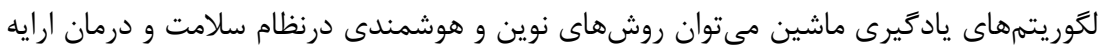

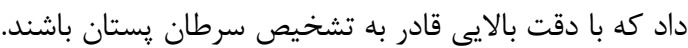

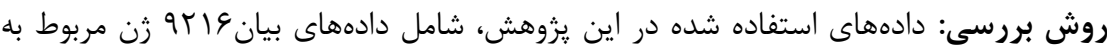

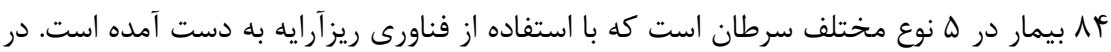

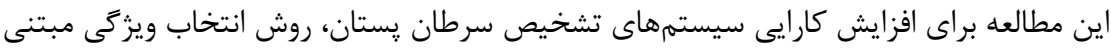

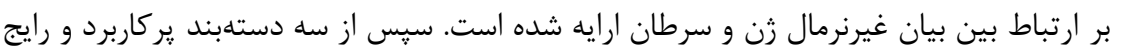

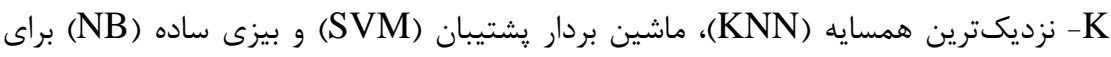
سنجش كارايى زنهاى انتخاب شده استفاده شد.

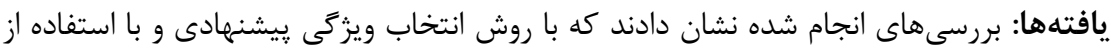

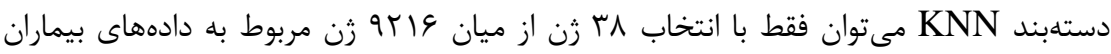

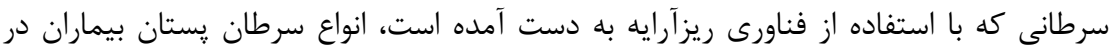

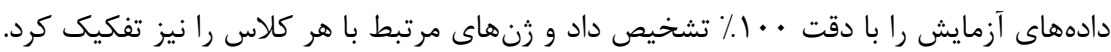

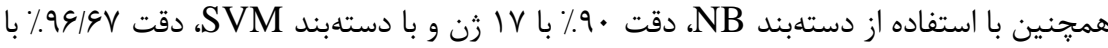

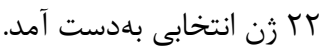
نتيجهَيرى: نتايج اين مطالعه نشان دادند كه روش انتخاب ويزَّى يِيشنهادى، با در نظر كرفتن

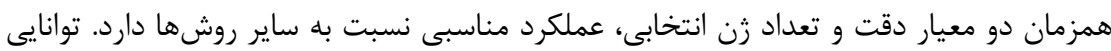

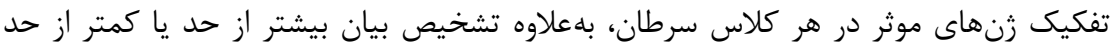

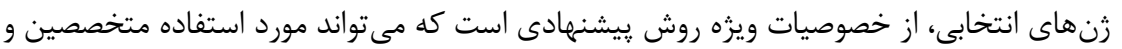

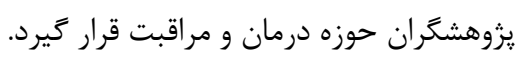

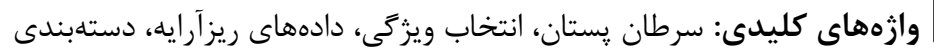

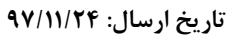

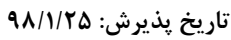

نشانى نويسنده مسئول:

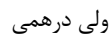
vderhami@yazd.ac.ir 
بيمارى است. مطالعات و روشهاى سنتى، تعداد زيادى از

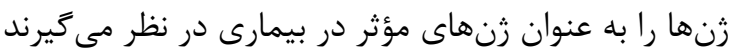

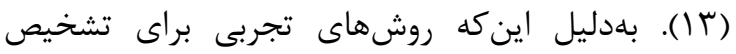

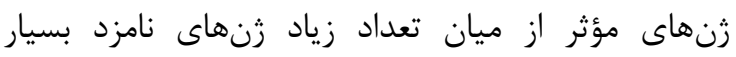

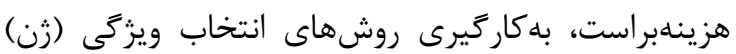

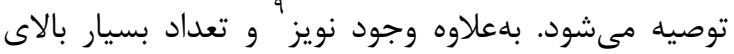

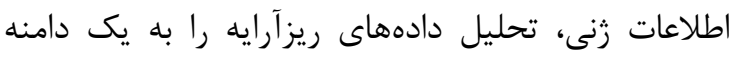

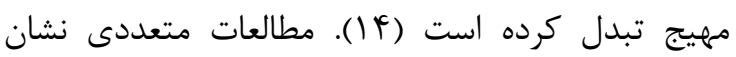
دادهاند كه تعداد بسيارى از دادههاى بيان زن ريزآ رآرايه DNA

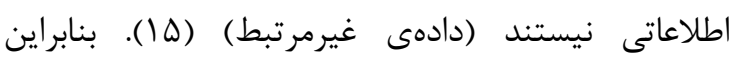

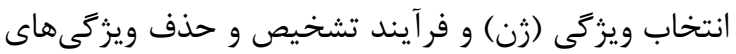

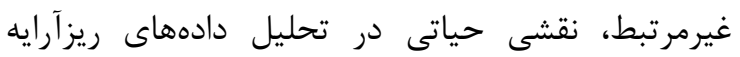

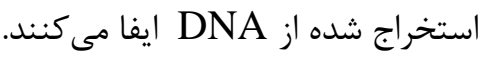
يافتهاى علمى به خصوص طى دو دها اخير ارتباط بين

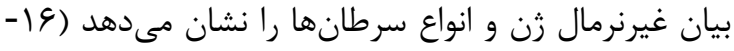

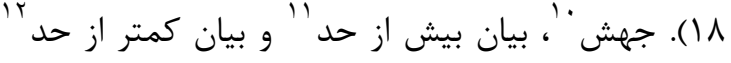

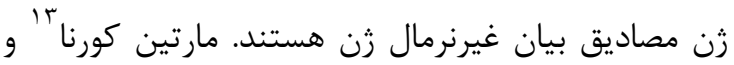

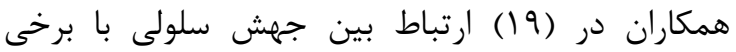

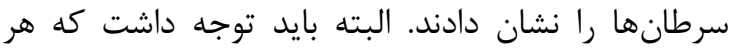
جهش منجر به سرطان نمىشود. زين العابدين و همكاران

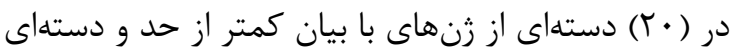
از زنها با بيان بيش از حد را براى تشخيص نوعى سرطان اندان

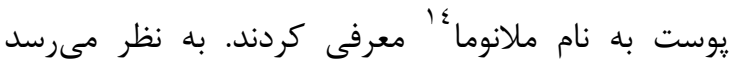

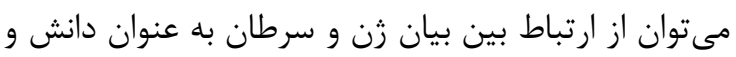
به صورت مهندسى معكوس در مسئله انتخاب زن درن دران

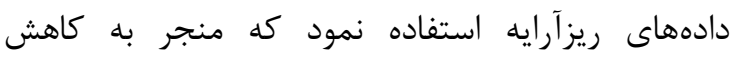
ييجيدگى مسئله خواهد شد.

\section{مواد و روشها}

مطالعه حاضر توصيفى و داده محور است كه به ارايه

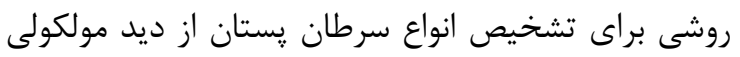
با استفاده از دادهاى بيان زن بيماران سرطانى يرداخته

\footnotetext{
${ }^{9}$ Noise

${ }^{10}$ Mutation

${ }^{11}$ Overexpression

${ }^{12}$ Underexpression or misexpression or less expression

${ }^{13}$ Martincorena

${ }^{14}$ Melanoma
}

سرطان يستان شايعترين سرطان و دومين عامل مرگ و

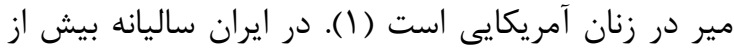

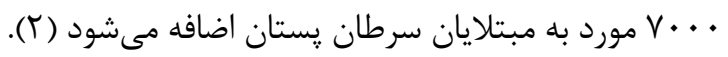
در اين بيمارى سلولهاى بدخيم (داراى رشد غير قابل

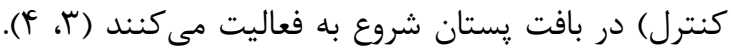

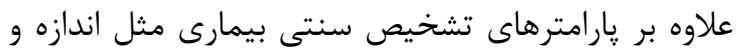

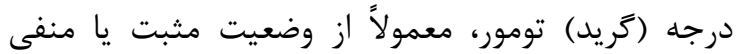

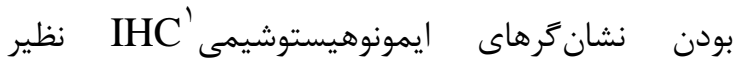
كيرندهاى براى تشخيص و مراقبت از بيماران سرطانى استفاده مىشود (ه، 9). از ديد أهاه مولكولى، انواع تومورهاى يستان

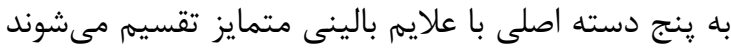

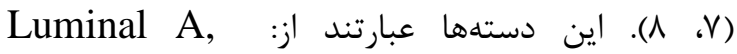
Luminal B, HER2 over-expression, Basal، Normal-like غير از كروه like, Normal-like ساير گروهها از نشانرهاى ايمونوهيستوشيمى متمايزى

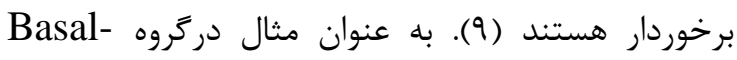

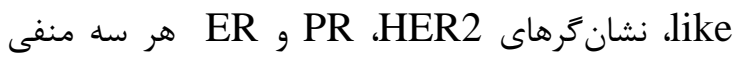

هستند. يكى از راههاى تشخيص انواع سرطان، استفاده از دادههاى

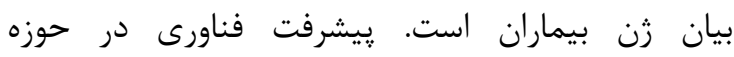
بيوانفورماتيك، به خصوص فناورى ريزآن رآرايه باعث شده كه

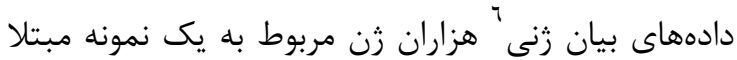
به سرطان به طور همزمان استخراج شود (• (1). البته اين

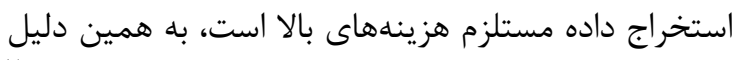

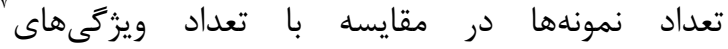
استخراجشده بسيار كم است. خنين دادههايى بهاختصار ناميده مىشود (1) HDLSS

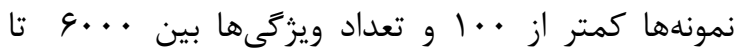

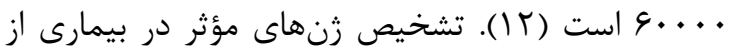

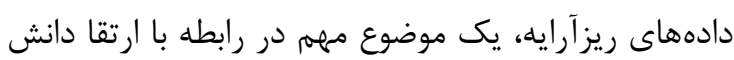

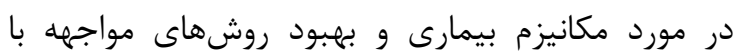

\footnotetext{
${ }^{1}$ Immunohistochemistry

${ }^{2}$ Estrogen receptor

${ }^{3}$ Progesterone receptor

${ }^{4}$ Human epidermal growth factor receptor 2

${ }^{5}$ Micro Array Data set

${ }^{6}$ Gene expression data

${ }^{7}$ Feature

${ }^{8}$ High Dimension Low Sample Size
} 
مقادير j از ا تا ه تغيير مى كند. Score $\left(f_{i} \mid C_{j}\right)$ ميزان

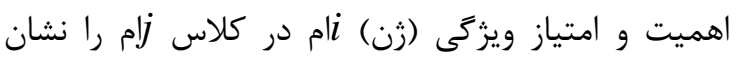

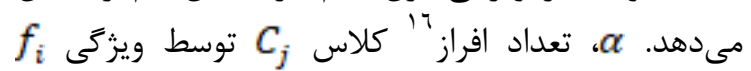

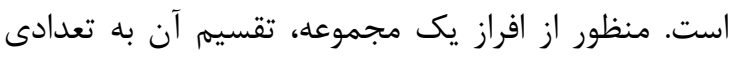

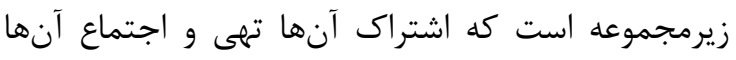

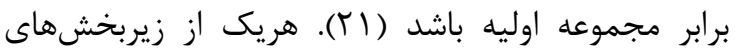
كلاس C C شامل نمونههايى است كه از نظر مقدارى كنار

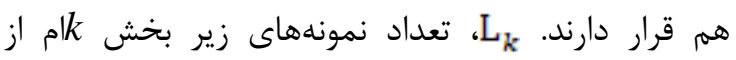

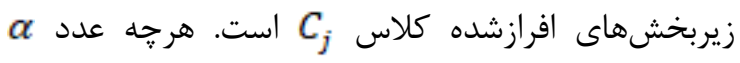

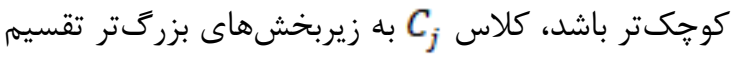

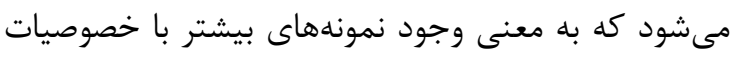

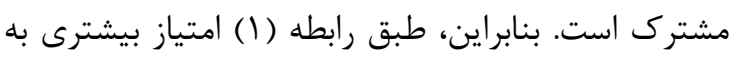

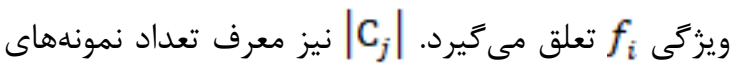

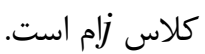

انتخاب زنها براساس امتياز بهدست آمده: بعد بعد از

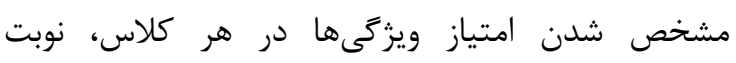

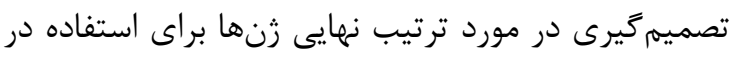
مدلهاى رايج يادكيرى مثل

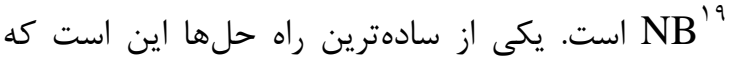

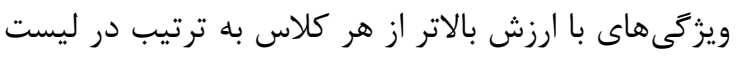

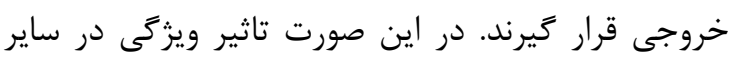
كلاسها در نظر كرفته نمى شورد

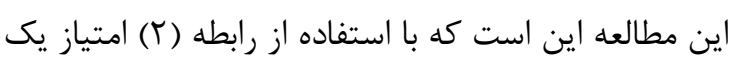

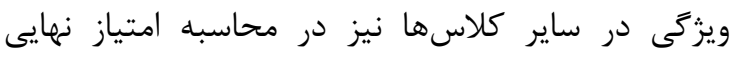

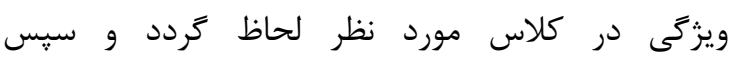

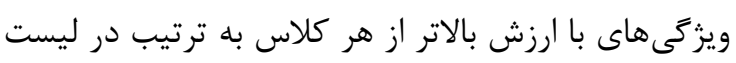
خروجى قرار تيرند.

$$
\operatorname{Score}\left(f_{i} \mid C_{j}\right)=\operatorname{Score}\left(f_{i} \mid C_{j}\right)+\beta * \sum_{\gamma \neq j} \operatorname{Score}\left(f_{i} \mid C_{r}\right)
$$

ضريب م ميزان مشاركت سايركلاسها در امتيازدهى را

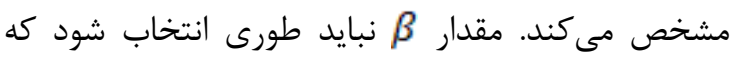

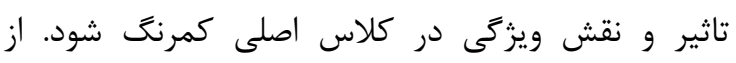

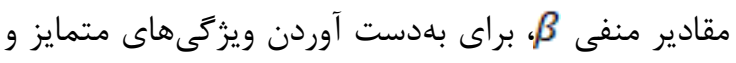

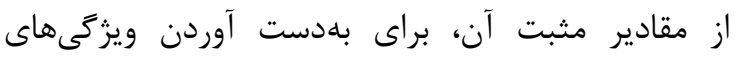

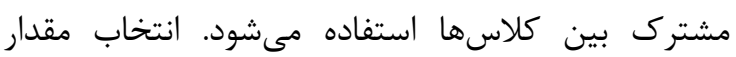

\footnotetext{
${ }^{16}$ Partition

${ }^{17}$ Support Vector Machine

${ }^{18} \mathrm{~K}$-nearest neighbor

${ }^{19}$ Naive Bayes
}

توصيف مجموعه دادهها: دادهاى استفاده شده در اين

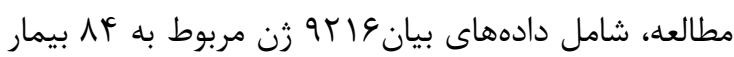

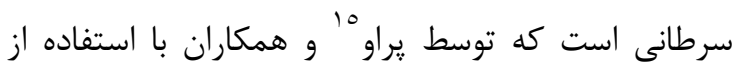

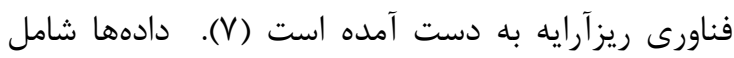

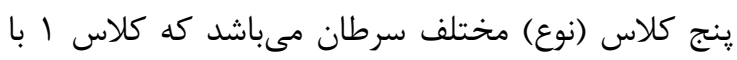

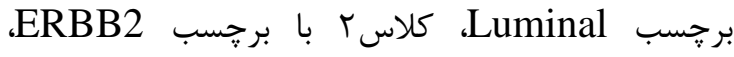
كلاسץ با برجسب Basal-like، كلاس بأ با برجسب

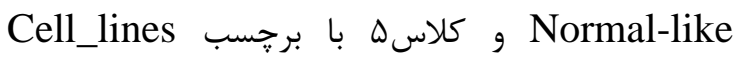

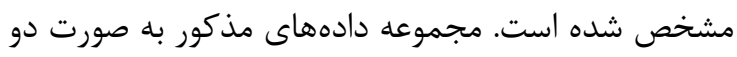

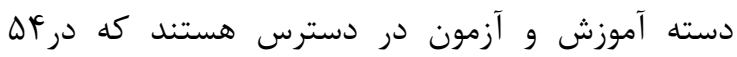

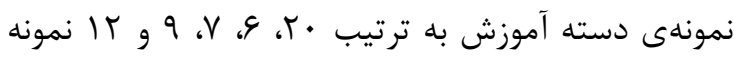

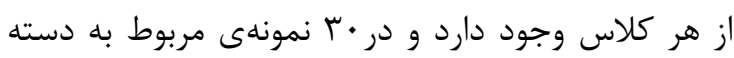

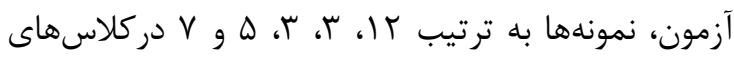

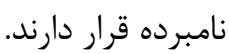

روش پيشنههادى: در اين بخش، از ارتباط بين بيان

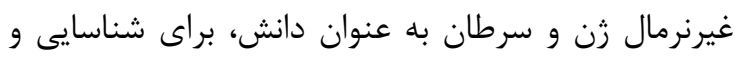
انتخاب زنهاى موثر در تشخيص سرطان يستان استفاده

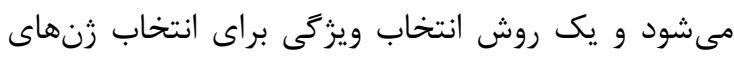

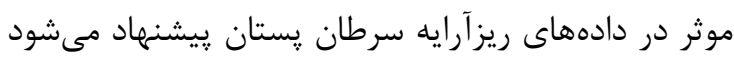

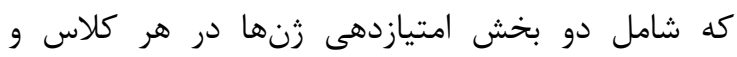

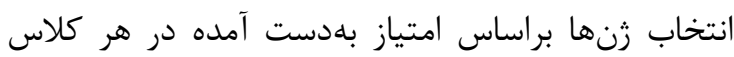

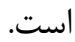
امتيازدهى زنها در هر كلاس: دادههاى بيان زن

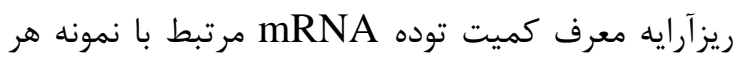
يك از بيماران است (r|)، بنابراين هر تغيير در بيان ثن

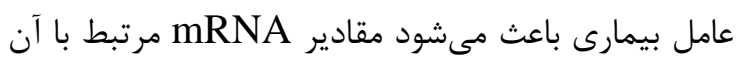

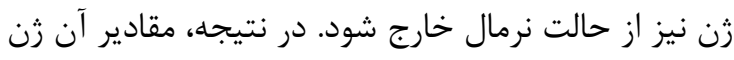

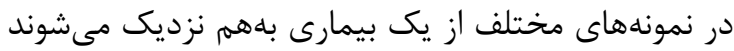

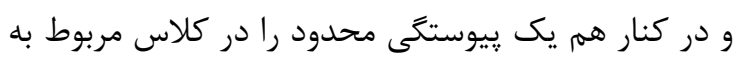

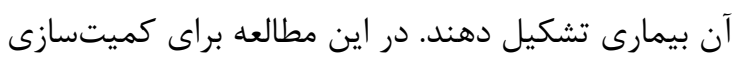

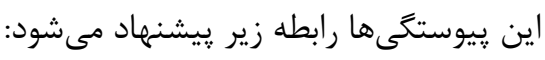

Score $\left(f_{i} \mid C_{j}\right)=\sum_{k=1}^{\infty} \frac{L_{k}}{\left|C_{j}\right|} \exp \left(\frac{L_{k}}{\left|C_{j}\right|}\right)$

كه fi

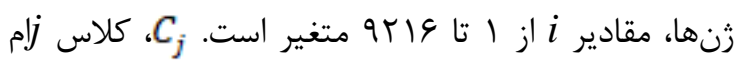
سرطان را نشان مىدهد كه با توجه به هـ كلاس سرطان،

${ }^{15}$ Perou 


\begin{tabular}{|c|c|c|c|c|}
\hline \multicolumn{5}{|c|}{ جدول ا: عملكرد روش پيشنهادى با توجه به معيار دقت } \\
\hline$\beta=-0.2$ & $\beta=1$ & $\beta=0.01$ & $\beta=0$ & 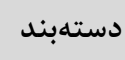 \\
\hline سז/ז1 & $q$. & 9 . & $\Lambda \varepsilon / 9 \vee$ & NB \\
\hline זس/ז9 & $\Lambda \& / 9 V$ & $94 / 9 V$ & $৭ ૬ \mid ૬ \vee$ & SVM \\
\hline سז/ז1 & $\Lambda \& / 8 V$ & $1 \ldots$ & $৭ \& \mid \& \vee$ & KNN \\
\hline \multicolumn{5}{|c|}{ جدول r: عملكرد روش پيشنهادى با توجه به معيار تعداد زن } \\
\hline$\beta=-0.2$ & $\beta=1$ & $\beta=0.01$ & $\beta=0$ & دستهبند \\
\hline TQ & IV & rq & q. & NB \\
\hline (i) & $r$. & tT & Fa & SVM \\
\hline r. & QI & r & Fr & KNN \\
\hline
\end{tabular}

توجه جدولهاى (1) و (Y)، در مجموع مدل هاى يادكيرى KNN , SVM

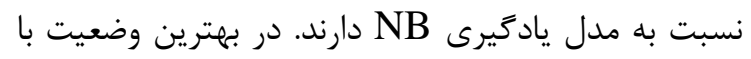

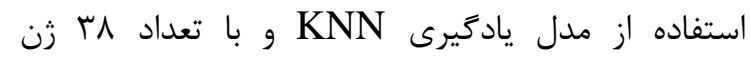

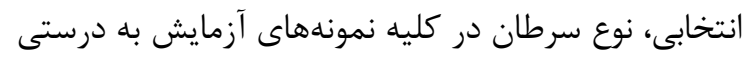
تشخيص داده شد. همجنين دقت قابل قبول و تعداد זr زن در مدل SVM بهدست آمد. جدولهاى (r)

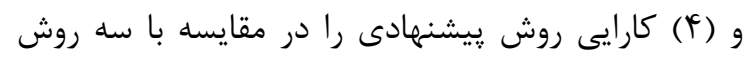

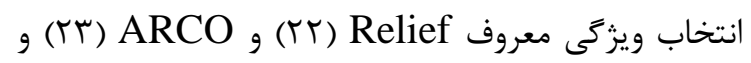
انتخائ (YY) FAST انتخابى و دستابندهاى مشابه) نشان مى مدهد. مقايسه نتايج بر اساس ميانكين خطاها در هر كلاس صورت كرفتهان

با توجه به جدول (Y))، تنها روش ARCO با دستهبند SVM و روش بيشنهادى در اين مطالعه با دستهبند KNN

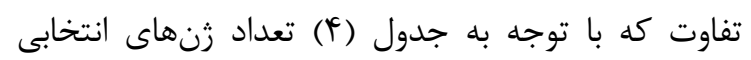

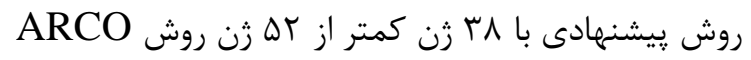
است. نكته مههم در مورد روش ڤيشنههادى نسبت به ساير

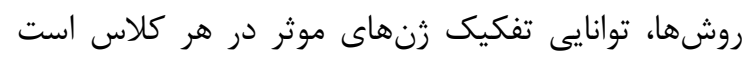

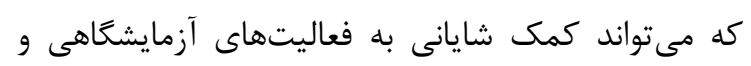

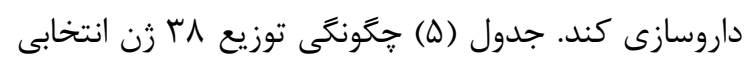
در كلاسهاى مختلف سرطان يستان را نشان مىدهد.
مناسب ß، به ماهيت دادها و نوع مدل يادكيرى استفاده شده براى دستهبندى "ب بستخى دارد.

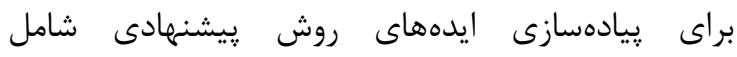

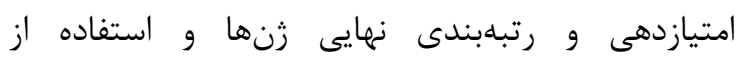

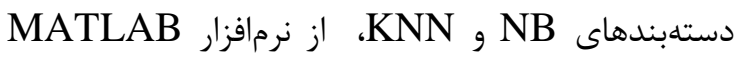
استفاده شده است. همجنين براى استفاده از دستهبند SVM

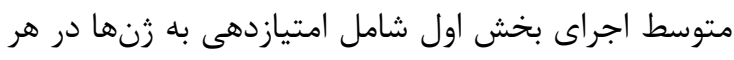
كلاس و رتبهدهى نهايى به آنها

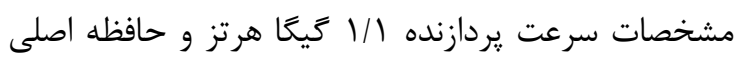

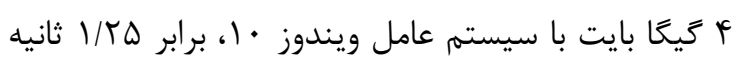
است. همجنين زمان متوسط اجراى بخش دوم شامل بالي استفاده از دستهبندهاى NB و

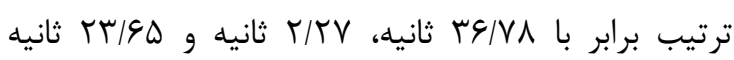

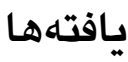

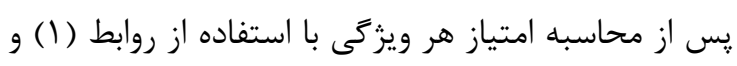

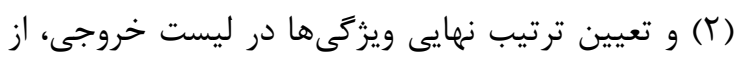

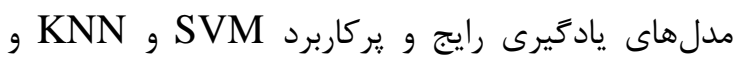

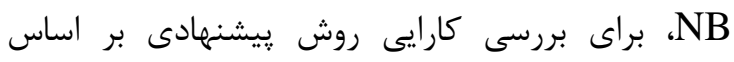

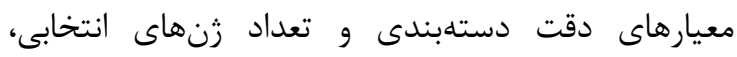

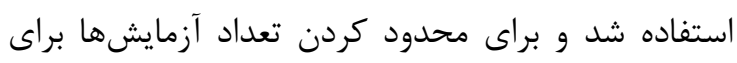

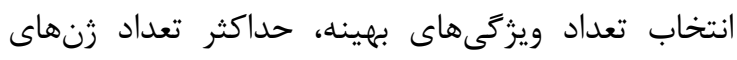

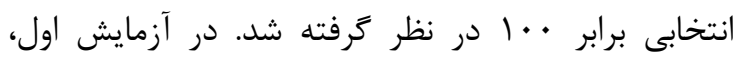

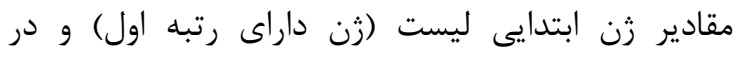

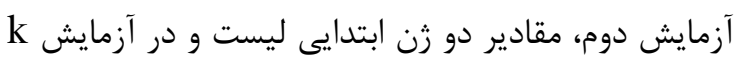

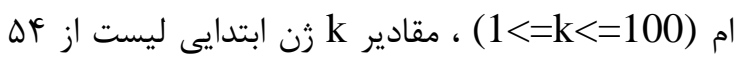

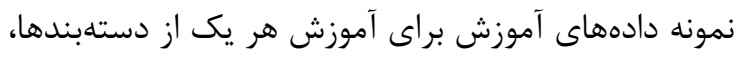

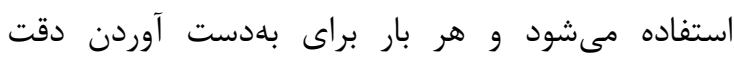

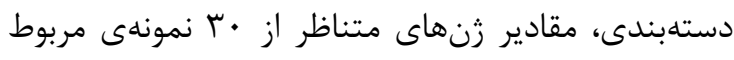

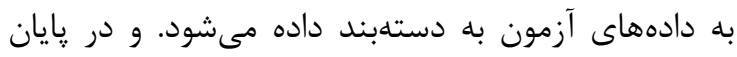

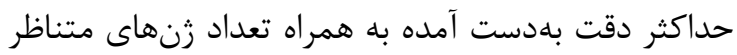

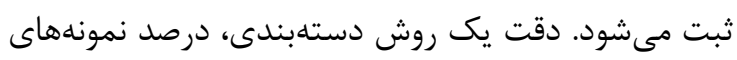

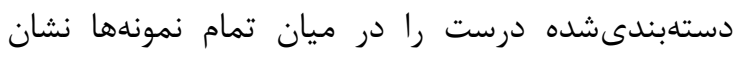

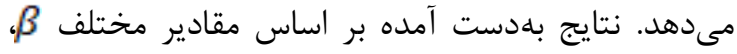
در جدولهاى ( (1) و (r) نشان داده شده است.

\footnotetext{
${ }^{20}$ Classification
} 


\begin{tabular}{|c|c|c|c|c|}
\hline \multicolumn{5}{|c|}{ جدول ؟!: حداقل ميانغين خطا در حداكثر +.ا ثن انتخابى } \\
\hline FAST* & ARCO* & ReliefF* & Proposed method & دستهبند \\
\hline.$/ 1 \mathrm{FF}$ & $.1 \cdot 1 \mathrm{~F}$ & $\cdot 119$ & $\cdot 199$ & NB \\
\hline$\cdot / \cdot \Delta r$ & $\cdot$ &.$/ 1 \mathrm{Fr}$ & $\cdot / \cdot r$ & SVM \\
\hline$\cdot / \cdot 11$ & $.1 \cdot 19$ & $\cdot / \cdot V^{F}$ & $\cdot$ & KNN \\
\hline
\end{tabular}

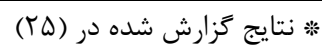

جدول F: تعداد زن هاى انتخابى هر روش با حداقل ميانغين خطا.

\begin{tabular}{|c|c|c|c|c|}
\hline FAST* & ARCO* & ReliefF* & Proposed method & دستهبند \\
\hline q & $8 \Lambda$ & AT & IV & NB \\
\hline vq & $\Delta r$ & $\Delta V$ & tr & SVM \\
\hline GT & $\Delta \Delta$ & $9 \vee$ & rی & KNN \\
\hline
\end{tabular}

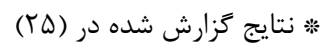

جدول ه: توزيع ^^ץ ثن انتخابى با استفاده از روش بيشنهادى در كلاسهاى مختلف سرطان يستان

\begin{tabular}{|c|c|c|c|c|c|c|c|c|}
\hline \multicolumn{8}{|c|}{ شماره زن } & \multirow{2}{*}{ كلاس سرطان } \\
\hline G4450 & G3150 & G8506 & G6797 & G7961 & G868 & G7797 & G9111 & \\
\hline & G2188 & G1379 & G6595 & G1054 & G7133 & G886 & G8921 & ERBB2 \\
\hline G4805 & G6243 & G6410 & G4211 & G2452 & G6623 & G4380 & G6802 & Basal-like \\
\hline G6554 & G2951 & G6606 & G5342 & G322 & G1756 & G74 & G1280 & $\begin{array}{l}\text { Normal- } \\
\text { like }\end{array}$ \\
\hline & G7625 & G2030 & G8137 & G5651 & G6385 & G8949 & G4919 & Cell-lines \\
\hline
\end{tabular}

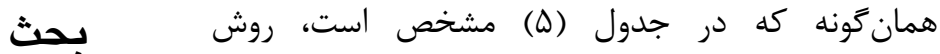
در روش زيشنهادى در اين مطالعه، تاثير هر زن در هريك از كلاسهاى سرطان پِّتان به طور جداگانه بررسى شد.

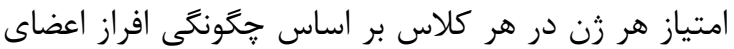

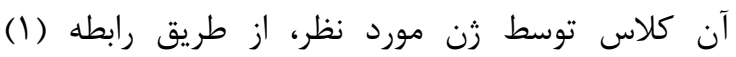
محاسبه شد. امتياز بهدست آمده براى در نظر گرفتن تاثير زنهاى مشترك، توسط رابطه (r) اصلاح شد و در نهايت، زنهاى موثر در هر كلاس به ترتيب امتياز در ليست

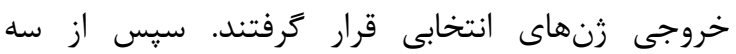

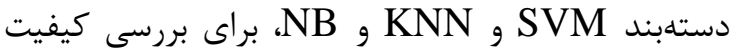
زنهاى انتخابى در تشخيص انواع سرطان يستان، استفاده

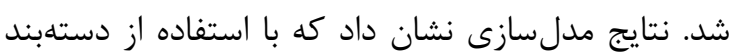

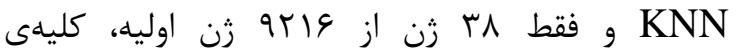
نمونههاى سرطان يستان از مجموعه دادههاى آزمايش به درستى تشخيص داده شد. در اين بخش كارايى روش لمون ييشنهلادى بر اساس معيارهاى دقت دستهبندى و تعداد زنهاى انتخابى، با تعدادى از روشهاى مرتبط كه آنها نيز روى مجموعه دادهاى مورد بحث اين مقاله اعمال

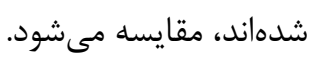

ييشنهادى توانسته است زنهاى موثر در هر كلاس را به

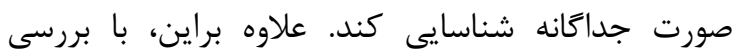
بيشتر رنهاى موثر در هر كلاس، زنهاى با بيان بيشتر يا

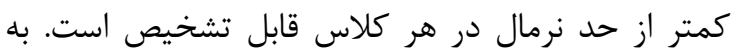

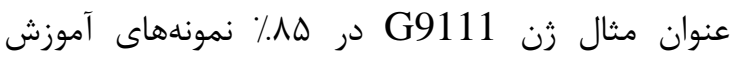

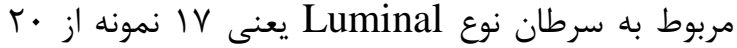
نمونه، بيان بيش از حد داشته است.

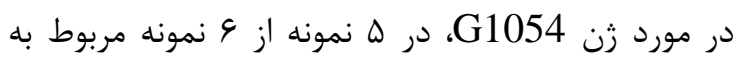
سرطان نوع ERBB، بيان زنى بيشتر نسبت به ساير نمونهها مشاهده گرديد. در سرطان نوع Basal-like،

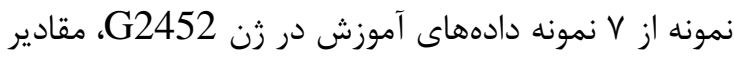
بيان زنى بالاتر نسبت به ساير نمونههاى انواع ديخر سرطان

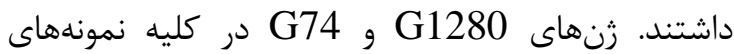
كلاس نوع Normal-like بيان بيش از حد نرمال

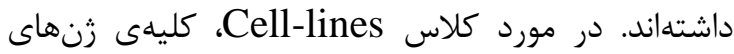
مشخص شده، بيان زن كمتر از حد نرمال در با نمونه مربوطه داشتند. 
زو و همكاران در (•"ا)، با بهرهخيرى از مفهوم آنترويى و

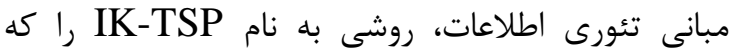

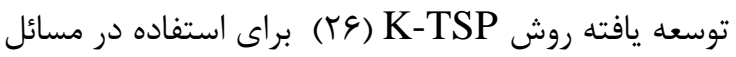

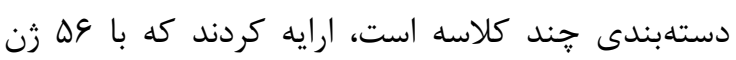

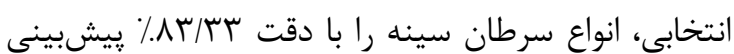

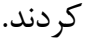

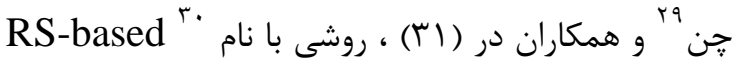

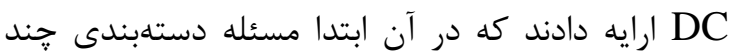
كلاسه را بر اساس روش باينرى تبديل كردند. سيس معيارهايى بر اساس مبانى

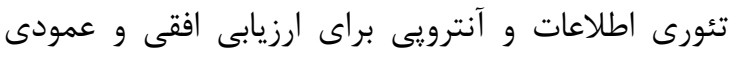

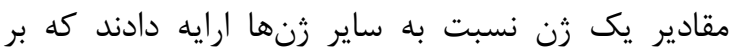
اساس آنها در كنار معيارى براى ارزيابى نسبى مقادير

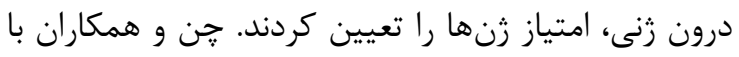

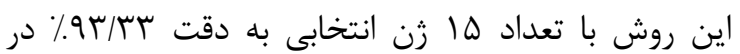
تشخيص درست سرطان پستان دست يافتند كه از نظر

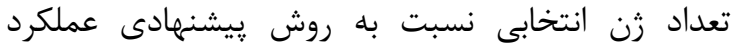

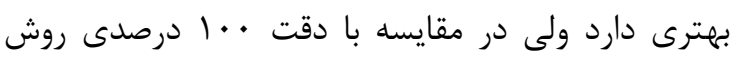
بيشنهادى، كارايى پِإيينترى دارد.

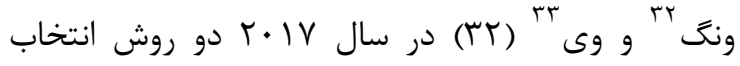

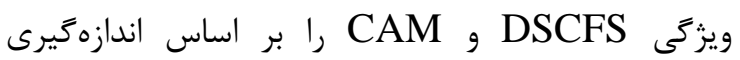
توانايى يك ويزگى در دستهبندى زير مسايل دو كلاسه و مفهوم مكمل بودن ويزگى ها ارايه كردند. آنها با و

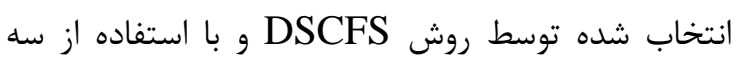

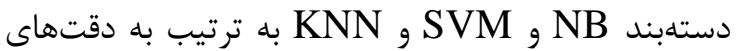

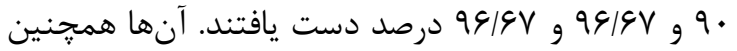
با لr ال زن انتخاب شده توسط روش CAM و و با استفاده

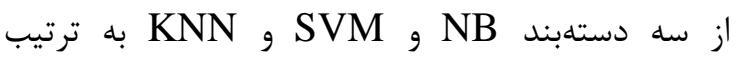

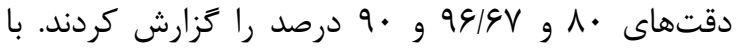

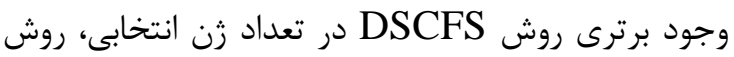

بيشنهادى با توجه به معيار دقت، عملكرد بهترى دارد دارد.

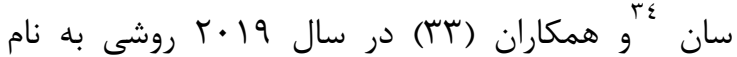
ECOC-MDC جندكلاسه به دستهبندى برى دوكلاسه بر اساس مفاهيم

\footnotetext{
${ }^{29}$ Chen

${ }^{30}$ Relative simplicity based direct classification

${ }^{31}$ One versus rest

${ }^{32}$ Wang

${ }^{33}$ Wei

${ }^{34}$ sun
}

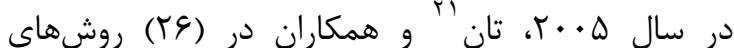
را HC-K-TSP و بر مبناى مقايسه نسبى مقادير جفت زنها ارايه كردند كه توسعه يافته روش

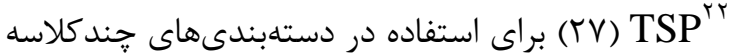
است. آنها با استفاده از روشهاى فوق به ترتيب با انتخاب

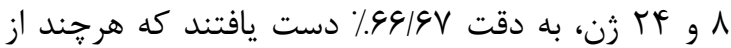

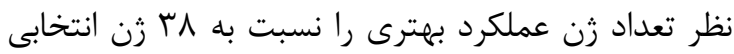

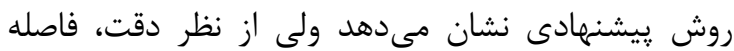

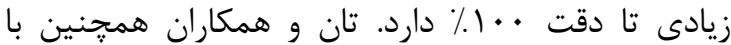
نرمافزار

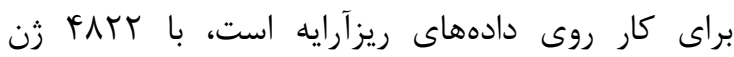
انتخابى، انواع سرطان سينه را با دقت سبراسو درصد

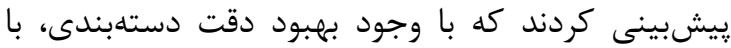
تعداد Y Y Y F زن انتخابى عملكرد مناسبى ندارد.

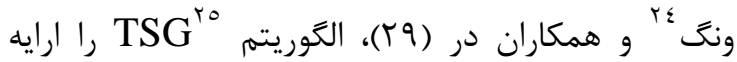

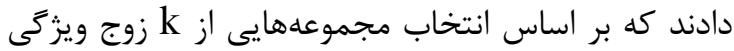

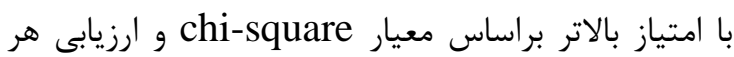

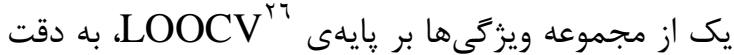
19/\&V

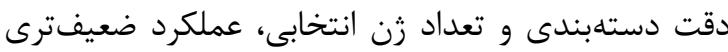

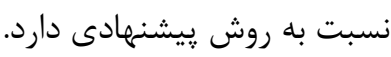

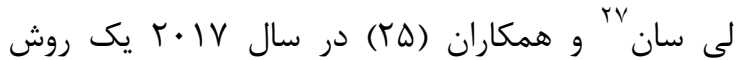
انتخاب ويزگ لهى به نام AVC را بر اساس منحنى

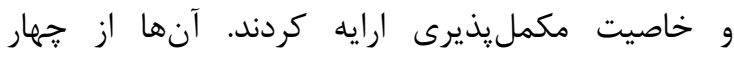
دستهبند SVM و Fr زن انتخاب شده توسط AVC استفاده كردند. نتايج

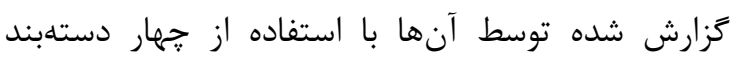

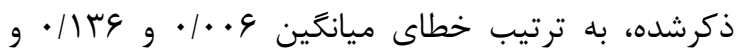

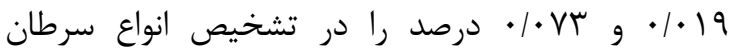

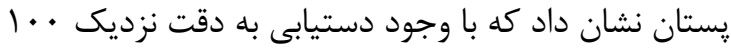

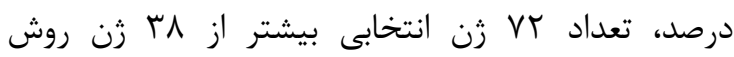

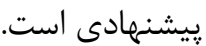

\footnotetext{
${ }^{21}$ Tan

${ }^{22}$ Top scoring pair

${ }^{23}$ Prediction analysis of microarrays

${ }^{24}$ Wang

${ }^{25}$ Top scoring genes

${ }^{26}$ Leave-one-out cross validation

${ }^{27}$ Wang

${ }^{28}$ Receiver Operator Characteristic
} 
در اين مطالعه، از ارتباط بين بيان غيرنرمال زن و سرطان

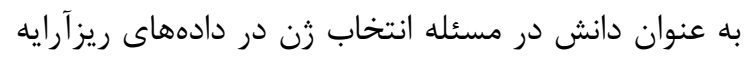

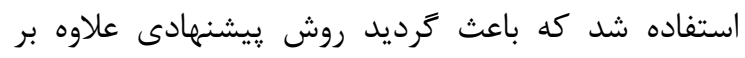

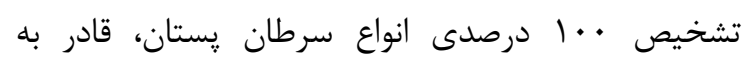

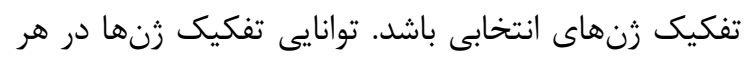
كلاس سرطان بهعلاوه تشخيص بيان بيشتر از حد يا كمتر

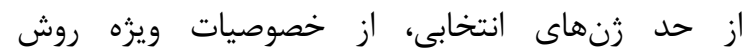

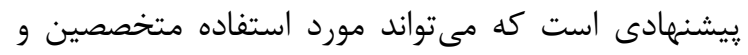
يزوهشكران حوزه تشخيص و درمان بيمارى سرطان

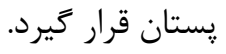

\section{تقدير و تشكر}

اين يزوهش نتيجه بخشى از فعاليتهاى صورت كرفته در

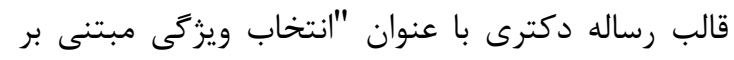
تئورى اطلاعات براى انتخاب زنهاى موثر در دران دادههاى

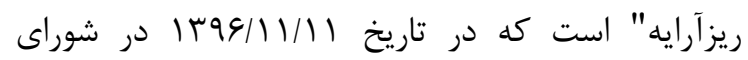

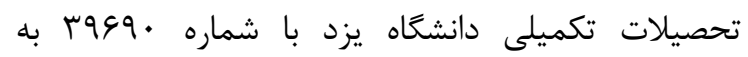

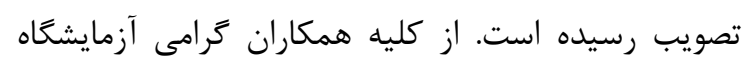

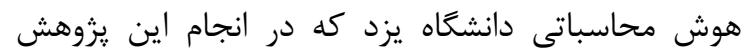
همراهى نمودند، تشكر و قدردانى مىشود.

\section{تعارض منافع}

نويسندًان اعلام مىدارند كه هيج تعارض منافعى در

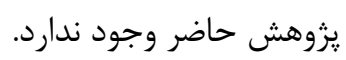

\section{References}

1. Smith RA, Andrews KS, Brooks D, Fedewa SA, Manassaram-baptiste D, Saslow D, et al. Cancer Screening in the United States, 2018: A Review of Current American Cancer Society Guidelines and Current Issues in Cancer Screening. CA Cancer J Clin. 2018;68(4):297-316.

2. Enayat R, Salehiniya H. An investigation of changing patterns in breast cancer incidence trends among Iranian women. J Sabzevar Univ Med Sci. 2015;22(1):27-35.

3. Wang YA, Johnson SK, Brown BL, McCarragher LM, Al-Sakkaf K, Royds JA, et al. Enhanced anti-cancer effect of a phosphatidylinositol-3 kinase inhibitor and doxorubicin on human breast epithelial cell lines with different p53 and oestrogen receptor status. Int $\mathrm{J}$ Cancer.
קيجيدگى دادهها ارايه دادند. آنها از سه روش انتخاب

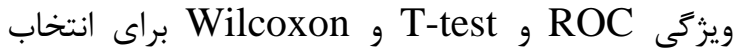
زنهاى با ارزشتر استفاده كردند. آنها با استفاده از روش و ECOC-MDC

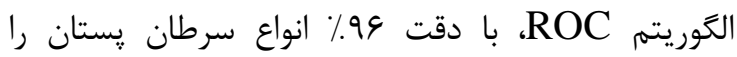

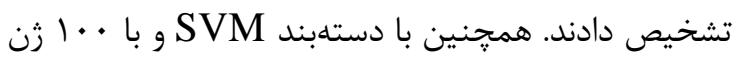

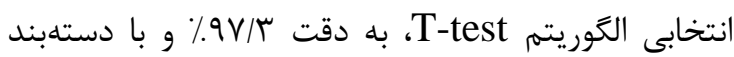

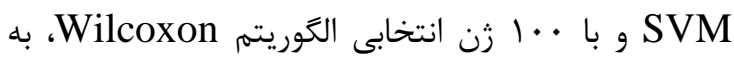
دقت 91/V دست يافتند. در مجموع دست يافتن به دقت · · ا درصدى، نقطه قوت

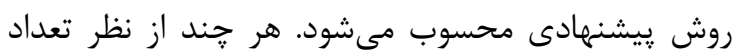
زنهاى انتخابى، برخى روشهاى ذكر شده عملكرد بهترى داشتند ولى با در نظر گرفتن همزمان دو يارامتر دقت رقائ دستهبندى و تعداد زن انتخابى، روش ييشنهادى عملكرد قابل قبولى نسبت به ساير روشها دارد. علاوه بر اين، با توجه به اينكه امتياز هر رن در در هر كلاس روس

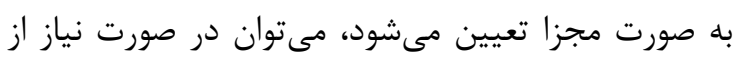

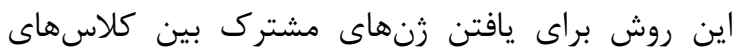
بيمارى استفاده كرد. به اين ترتيب كه زنهايى كه رنه داريى امتياز بالا در دو يا جند كلاس باشند، مىتوانند به عنوان رنهاى نامزد براى مشخص شدن زنهاى موثر مشترك، مورد مطالعه قرار زيرند. نتبحه گیرى 2008;123(7):1536-44.

4. Sheikhpour R, Ghassemi N, Yaghmaei P, Ardekani JM, Shiryazd M. Immunohistochemical assessment of P53 protein and its correlation with clinicopathological characteristics in breast cancer patients. Indian J Sci Technol. 2014;7(4):472-9.

5. Vallejos CS, Gómez HL, Cruz WR, Pinto JA, Dyer RR, Velarde R, et al. Breast Cancer Classification According to Immunohistochemistry Markers: Subtypes and Association With Clinicopathologic Variables in a Peruvian Hospital Database. Clin Breast Cancer. 2010;10(4):294-300.

6. Cheang MCU, Chia SK, Voduc D, Gao D, Leung S, Snider J, et al. Ki67 index, HER2 status, and 
prognosis of patients with luminal B breast cancer. JNCI J Natl Cancer Inst. 2009; 101(10): 736-50.

7. Perou CM, Sørlie T, Eisen MB, Van De Rijn M, Jeffrey SS, Rees CA, et al. Molecular portraits of human breast tumours. Nature. 2000; 406(6797): 747-52.

8. Sørlie T, Perou CM, Tibshirani R, Aas T, Geisler $\mathrm{S}$, Johnsen $\mathrm{H}$, et al. Gene expression patterns of breast carcinomas distinguish tumor subclasses with clinical implications. Proc Natl Acad Sci. 2001; 98(19):10869-74.

9. Dai X, Li T, Bai Z, Yang Y, Liu X, Zhan J, et al. Breast cancer intrinsic subtype classification, clinical use and future trends. Am J Cancer Res. 2015; 5(10):2929-43.

10. Piatetsky-Shapiro G, Tamayo P. Microarray data mining: facing the challenges. ACM SIGKDD Explor Newsl. 2003; 5(2):1-5.

11. Zhang L, Lin X. Some considerations of classification for high dimension low-sample size data. Stat Methods Med Res. 2013; 22(5):537-50.

12. Guyon I, Elisseeff A. An Introduction to Variable and Feature Selection. J Mach Learn Res. 2003; 3(3):1157-82.

13. Glazier AM. Finding Genes That Underlie Complex Traits. Science. 2002; 298(5602): 23459.

14. Saeys Y, Inza I, Larrañaga P. A review of feature selection techniques in bioinformatics. Bioinformatics. 2007; 23(19):2507-17.

15. Golub TR, Slonim DK, Tamayo P, Huard C, Gaasenbeek M, Mesirov JP, et al. Molecular classification of cancer: Class discovery and class prediction by gene expression monitoring. Science. 1999; 286(5439):531-7.

16. Tsafrir D, Bacolod M, Selvanayagam Z, Tsafrir I, Shia J, Zeng Z, et al. Relationship of gene expression and chromosomal abnormalities in colorectal cancer. Cancer Res. 2006; 66(4): 2129-37.

17. Prelich G. Gene overexpression: uses, mechanisms, and interpretation. Genetics. 2012; 190(3): 841-54.

18. Gray JW, Collins C. Genome changes and gene expression in human solid tumors. Carcinogenesis. 2000; 21(3):443-52.

19. Martincorena I, Campbell PJ. Somatic mutation in cancer and normal cells. Science (80). 2015; 349(6255):1483-9.

20. Zainulabadeen A, Yao P, Zare $\mathrm{H}$. Underexpression of specific interferon genes is associated with poor prognosis of melanoma.
PLoS One. 2017; 12(1):e0170025.

21. Pinter CC. A Book of SET THEORY. Dover Publications; 2014.

22. Zhao Z, Wang L, Liu H, Ye J. On Similarity Preserving Feature Selection. IEEE Trans Knowl Data Eng. 2013; 25(3):619-32.

23. Wang $\mathrm{R}$, Tang $\mathrm{K}$. Feature Selection for Maximizing the Area Under the ROC Curve. In: 2009 IEEE International Conference on Data Mining Workshops. 2009; 400-5.

24. Chen X, Wasikowski M. FAST: A Roc-based Feature Selection Metric for Small Samples and Imbalanced Data Classification Problems. In: Proceedings of the 14th ACM SIGKDD International Conference on Knowledge Discovery and Data Mining. 2008; 124-32.

25. Sun L, Wang J, Wei J. AVC: Selecting discriminative features on basis of AUC by maximizing variable complementarity. BMC bioinformatics. 2017; 18(3):50.

26. Tan AC, Naiman DQ, Xu L, Winslow RL, Geman D. Simple decision rules for classifying human cancers from gene expression profiles. Bioinformatics. 2005; 21(20):3896-904.

27. Geman D, d'Avignon C, Naiman DQ, Winslow RL. Classifying gene expression profiles from pairwise mRNA comparisons. Stat Appl Genet Mol Biol. 2004; 3(1):1-19.

28. Tibshirani R, Hastie T, Narasimhan B, Chu G. Diagnosis of multiple cancer types by shrunken centroids of gene expression. Proc Natl Acad Sci. 2002; 99(10):6567-72.

29. Wang H, Zhang H, Dai Z, Chen M, Yuan Z. TSG: a new algorithm for binary and multi-class cancer classification and informative genes selection. BMC Med Genomics. 2013; 6(1):S3.

30. Zhou C, Wang S, Blanzieri E, Liang Y. An entropy-based improved k-top scoring pairs (TSP) method for classifying human cancers. African J Biotechnol. 2012;11(45):10438-45.

31. Chen Y, Wang L, Li L, Zhang H, Yuan Z. Informative gene selection and the direct classification of tumors based on relative simplicity. BMC Bioinformatics. 2016;17(1):44.

32. Wang S, Wei J. Feature selection based on measurement of ability to classify subproblems. Neurocomputing. 2017; 224:155-65.

33. Sun M, Liu K, Wu Q, Hong Q, Wang B, Zhang H. A novel ECOC algorithm for multiclass microarray data classification based on data complexity analysis. Pattern Recognit. 2019; 90: 346-62. 